Grand Valley State University

ScholarWorks@GVSU

\title{
Context-Based Assessment and Intervention for Problem Behavior in Children With Autism Spectrum Disorder
}

\author{
Sanja I. Cale \\ State University of New York \\ Edward G. Carr \\ State University of New York \\ Audrey Blakeley-Smith \\ University of Colorado at Denver and Health Sciences Center \\ Jamie S. Owen-DeSchryver \\ Grand Valley State University, owendesj@gvsu.edu
}

Follow this and additional works at: https://scholarworks.gvsu.edu/psy_articles

Part of the Psychology Commons

\section{ScholarWorks Citation}

Cale, Sanja I.; Carr, Edward G.; Blakeley-Smith, Audrey; and Owen-DeSchryver, Jamie S., "Context-Based Assessment and Intervention for Problem Behavior in Children With Autism Spectrum Disorder" (2009). Peer Reviewed Articles. 46.

https://scholarworks.gvsu.edu/psy_articles/46

This Article is brought to you for free and open access by the Psychology Department at ScholarWorks@GVSU. It has been accepted for inclusion in Peer Reviewed Articles by an authorized administrator of ScholarWorks@GVSU. For more information, please contact scholarworks@gvsu.edu. 
Context-Based

Assessment and

Intervention for

Problem Behavior in

Children With Autism

Spectrum Disorder
(C) 2009 SAGE Publications DOI: I0.I I77/0 | 45445509340775

http://bmo.sagepub.com

@SAGE

\title{
Sanja I. Cale', Edward G. Carr², Audrey Blakeley-Smith ${ }^{3}$, and Jamie S. Owen-DeSchryver ${ }^{4}$
}

\begin{abstract}
The present study used a context-based model of assessment and intervention to explore whether interventions that modify context result in reduction of problem behavior in ecologically valid settings (i.e., typical routines implemented by typical education personnel in neighborhood schools). The Contextual Assessment Inventory (CAI) and a postassessment interview were administered to parents and teachers of eight children with Autism Spectrum Disorder to identify problem contexts. Then, environmental modification techniques were implemented in three priority contexts: namely, transitions, termination of preferred activities, and presence of a feared stimulus. Our results demonstrated an almost complete elimination of problem behavior in the priority contexts as well as successful completion of activities and routines related to those contexts. We discuss the value of conceptualizing problem behavior as a function of context with respect to facilitating both assessment and intervention, and the need for enhancing breadth of effects to determine the larger impact of a contextbased approach on promoting meaningful behavior change in the community.
\end{abstract}

\section{Keywords}

autism, problem behavior, contextual assessment, contextual interventions

\footnotetext{
'State University of New York at Old Westbury

${ }^{2}$ formerly of State University of New York at Stony Brook

${ }^{3}$ University of Colorado at Denver and Health Sciences Center

${ }^{4}$ Grand Valley State University, Allendale, Michigan
} 
Children with developmental disabilities are more likely than typically developing children to exhibit problem behavior (Baker, Blacher, Crnic, \& Edelbrock, 2002). Such behavior has consistently been shown to decrease family quality of life (Koegel et al., 1992), increase likelihood of institutionalization (Bruininks, Hill, \& Moreau, 1988), and result in social isolation for the individuals involved (Horner et al., 1990). Given that problem behavior impedes positive clinical outcomes, the assessment of the factors evoking and maintaining such behavior is seen as a critical first step toward the development of effective interventions, particularly since meta-analyses of the extant research literature, including our own (Carr et al., 1999), suggest that assessment-based intervention is twice as likely to be successful as interventions not based on assessment.

The most common form of assessment, Functional Behavioral Assessment (FBA), focuses on identifying antecedents and consequences that control problem behavior (O'Neill et al., 1997). Over the years, a large research base (Carr, 1977; Iwata, Dorsey, Slifer, Bauman, \& Richman, 1982) has identified the common functions (consequences) of problem behavior that include attention (i.e., problem behavior maintained by the social reactions it evokes from others), escape (i.e., problem behavior maintained by its effectiveness in terminating aversive tasks and activities), tangible seeking (i.e., problem behavior maintained by promoting access to preferred items), and sensory reinforcement (i.e., problem behavior maintained by the internal or perceptual stimuli it generates).

In addition, antecedent discriminative stimuli, particularly task demands, have been identified as potential triggers for a variety of problem behaviors (Carr \& Durand, 1985; Carr, Newsom, \& Binkoff, 1980). Setting events are another class of antecedent variables impacting problem behavior. These events are defined as broad contextual variables that momentarily change the reinforcing or aversive properties of response consequences, thereby influencing likelihood that the response (e.g., problem behavior) will occur. The concept of establishing operation (Michael, 1982) or, more recently, motivating operation (Laraway, Snycerski, Michael, \& Poling, 2001/2002) serves to highlight one mechanism through which setting events are believed to exert their effect on behavior, namely, by altering the reinforcing effectiveness of a given stimulus. Thus, an establishing operation may increase the aversiveness of a stimulus, thereby enhancing negative reinforcement of any behavior (including problem behavior) that successfully terminates the stimulus.

Researchers have identified several major categories of setting events: biological, activities/routines, and social (Bijou \& Baer, 1978). Biological setting events include illness, fatigue, physical discomfort, and drugs (Carr, 
Smith, Giacin, Whelan, \& Pancari, 2003). Activities/routines include setting events such as the pacing of academic demands, the amount of choice a child has in an activity, and the scheduling of activities in a child's day (Dunlap, Kern-Dunlap, Clarke, \& Robbins, 1991). Social setting events include crowding, the presence or absence of specific people, and being teased (Touchette, MacDonald, \& Langer, 1985).

Consider a social setting event such as being teased. In illustration, a child may generally find academic demands (discriminative stimuli) mildly aversive and periodically display problem behavior, such as tantrums, in order to terminate (i.e., escape from) the demands. However, if the child has recently been teased (i.e., a social setting event), the same demands may become even more aversive, thereby enhancing the degree to which escape from demands has reinforcing properties. Thus, escape behaviors (tantrums) are more strongly reinforced and, over time, these behaviors become progressively more frequent in contexts that involve the presence of demands and a recent experience of having been teased.

In sum, existing research has identified a broad array of discriminative stimuli and setting events that, collectively, constitute the context for problem behavior, a context that can have a profound impact on such behavior. The purpose of the present series of studies was to test, in a systematic way, the notion that problem contexts produce problem behavior and, therefore, by modifying problem contexts, we should be able to reduce or eliminate problem behavior. Because of the centrality of education in the treatment of autism, we chose to test the context-based model of assessment and intervention within typical neighborhood school settings involving typical education personnel as naturalistic intervention agents dealing with common school-related situations. Ecological validity, therefore, was the major focus.

\section{Overview}

Three studies were conducted to examine and remediate three common contexts associated with problem behavior: (a) transitioning between settings or activities, (b) the termination of a preferred activity, and (c) the presence of a feared stimulus.

Each study had five components. First, participants were selected based on predetermined inclusion criteria, uniquely specified in each of the three studies described shortly, and parental completion of the Contextual Assessment Inventory (CAI), an instrument used to identify discriminative stimuli and setting events (i.e., contexts) that are plausibly related to problem behavior. (The CAI is elaborated upon in detail in Study 1.) Specific contexts were 
selected, for each participant, on the basis of a postassessment interview (i.e., post-CAI) with relevant stakeholders (i.e., parents and teachers). Second, a baseline observation was conducted to confirm the presence of problem behavior in the identified context. Third, the intervention package was developed based on the assessment information and the intervention agent was trained to implement it. Fourth, the intervention package was delivered and data were collected on behavioral outcomes. Fifth, ancillary posttest measures of social validity were administered.

\section{Study I:Transitions Between Settings or Activities as a Context for Problem Behavior}

Method

In this study as well as the two subsequent studies, a multiple baseline design across three participants (Hersen \& Barlow, 1976) was conducted to examine the impact of environmental modification on problem behavior.

\section{Participant and Context Selection}

Participants were identified through consultation with clinical and educational staff and were required to meet the following inclusion criteria: (a) diagnosis of an autism spectrum disorder made by an independent psychiatrist or licensed psychologist using DSM-IV criteria, (b) presence of problem behavior in the home, school, and/or community, (c) availability for participation in sessions three times per week, and (4) parental consent. All three participants selected were school-aged children, ages 5 to 8 years old, who received special education services in different public schools in Long Island, New York. IRB approval and parental consent were obtained for all participants in this and the two subsequent studies.

Parents who nominated their children for the study were asked to complete the Contextual Assessment Inventory (CAI; Carr, Ladd, \& Schulte, 2008; McAtee \& Carr, 2004). The CAI is designed to help families and teachers identify discriminative stimuli and setting events (i.e., contexts) that evoke problem behavior in home, school, and community settings. The CAI is a rating scale comprised of three general categories of contextual factors (i.e., social, activities/routines, biological), involving eight exemplars of each category (e.g., for activities/routines: difficulty transitioning between settings or activities). In the present study, parents were asked to endorse the likelihood of problem behavior for each context using a 5-point Likert-type 
scale, with " 1 " indicating that problem behavior was not likely to occur in that context, and " 5 " indicating that it was very likely to occur.

Following administration of the CAI, a postassessment interview based on the format developed by O'Neill et al. (1997) was conducted with the parent to identify, in greater detail, the contexts that evoked problem behavior. Four questions were posed to each parent: (a) What specific activity was most/least likely to trigger problem behavior? (b) With whom was problem behavior most/least likely to occur? (c) In what setting was problem behavior most/ least likely to occur? (d) During what time of day was problem behavior most/least likely to occur? For each child, following consultation with caregivers, a priority context based on the interview was identified for intervention.

In this and subsequent studies, mothers served as the informants because, over a period of 1 to 2 years, they had been notified by school staff, on a continuing basis, of multiple disciplinary referrals as well as the situations that precipitated those referrals. For the three children in the present study, all three mothers indicated that their child was very likely to show problem behavior when asked to transition between settings or activities at school. Mothers reported that the children's teachers noted significant problem behavior, when transitioning, that was disruptive to the school routine, and merited immediate intervention. Therefore, the postassessment interview was also conducted with the children's teachers/classroom staff to confirm the presence of problem behavior in this context. During this interview, the teachers were also asked to indicate whether there were any features of the transition context that made problem behavior less likely to occur.

Participant I: Darrell. Darrell was an 8-year-old boy diagnosed with Asperger's Syndrome (Full Scale IQ = 110, Wechsler Intelligence Scale for Children, Fourth Edition), who was placed in an inclusion third-grade classroom where he received instruction with 16 typical peers as well as two peers with other disabilities. During the postassessment interview (following CAI administration), both Darrell's mother and his third-grade teacher indicated that Darrell was most likely to exhibit problem behavior in school when asked to transition away from the classroom setting. Specifically, the teacher reported that Darrell frequently engaged in problem behavior (i.e., selfinjury, screaming) when asked to leave the classroom for his occupational therapy (OT) session in which he was required to carry out a variety of difficult fine motor tasks related to writing. At the time of the interview, Darrell was no longer receiving the mandated OT services on his individualized education plan (IEP) because he refused to leave the classroom. The teacher also noted that Darrell was less likely to exhibit problem behavior when asked to 
leave the room accompanied by his peers or when asked to leave for short durations (e.g., to pick up an item from the office and return to class).

Participant 2: Joanne. Joanne was a 5-year-old girl diagnosed with Pervasive Developmental Disorder (Full Scale IQ $=104$, Wechsler Preschool and Primary Scale of Intelligence-Revised), who was placed in a regular kindergarten class with the support of a full-time aide. During the postassessment interview, Joanne's mother stated that her daughter was most likely to exhibit problem behavior during transitions at school. Her teacher confirmed this report, stating that Joanne had the greatest difficulty transitioning between activities, particularly from her individual OT session to the gym. The therapy session often overlapped with the first 5 minutes of the physical education (PE) period, resulting in Joanne missing instructional information for the PE activities. Upon returning to the PE class, Joanne would drop to the floor, screaming and kicking. Due to scheduling difficulties, the time of the OT session could not be changed.

Participant 3: Anna. Anna was a 5-year-old girl who was diagnosed with Pervasive Developmental Disorder (Full Scale IQ $=76$, Wechsler Preschool and Primary Scale of Intelligence-Revised). She was placed in a regular kindergarten class with the support of a full-time aide. Anna's mother and teacher noted that when Anna was asked to transition from her individual and group speech sessions back to the classroom, she became upset because classroom activities had often begun by the time of her return. Upon returning to the classroom, Anna would yell, cry, and demand that the classroom activity be started over.

\section{Baseline Observations}

During this component, the investigator (senior author) and a second observer, who was a graduate student in clinical psychology, directly observed the contexts identified to confirm that the noted transitions were indeed associated with the occurrence of problem behavior, and that a low percentage of transition steps was completed. A task analysis was developed to measure each student's progress in completing the transition. Specifically, the sequence of transition steps was defined as follows: Upon presentation by the teacher of a verbal instruction to transition: (a) the child stood up from his/her seat and moved at least .3 meters in the direction of the new location; (b) the child continued to move by leaving the current classroom or setting; (c) the child proceeded to walk down the hallway; (d) the child entered the new classroom or destination setting; and, finally, (e) the child engaged in the 
activity associated with the new classroom or destination setting for at least 3 min, indicating a successful transition.

Baseline data for Darrell were collected in the general education classroom setting where the occupational therapist asked Darrell to leave the room to attend the OT session. Baseline data for Joanne were collected in the OT room where her 1:1 aide asked her to go to gym. Baseline data for Anna were collected in the speech room where Anna was instructed to go back to her classroom by her 1:1 aide.

To ensure the safety of both the child and the supporting adult, we terminated a session contingent upon either of these two events: (a) occurrence of a single instance of "untolerated" problem behavior, defined as aggression (i.e., kicking, throwing items, squeezing the teacher's arm, pushing), selfinjury (i.e., hand to head punching or slapping), or more than $5 \mathrm{sec}$ of screaming, that is, tantrumming, or (b) three instances of "tolerated" problem behavior, defined as brief episodes (i.e., less than $5 \mathrm{sec}$ ) of screaming, verbal insults, and/or stomping feet on the floor (Carr \& Carlson, 1993). Tolerated problem behavior was deemed less serious and, therefore, up to three instances of such behavior were permitted prior to session termination.

\section{Response Recording}

During baseline and intervention, data were collected by hand (paper and pencil) for all primary target measures. The primary dependent variables were: (a) percentage of transition steps completed, (b) latency to session termination following the adult verbal instruction, and (c) number of sessions terminated due to problem behavior. The specific definitions of problem behavior used were those previously described under Baseline Observations. Percentage of transition completed was defined as the number of transition steps completed prior to session termination (i.e., due either to the occurrence of problem behavior or successful completion of the routine) divided by the total number of steps required to complete the routine, multiplied by 100 . Latency to session termination was defined as the amount of time that elapsed after the first verbal instruction was given to begin the transition and either (a) termination of the session due to problem behavior or (b) successful completion of the transition.

Throughout the baseline sessions, observers noted whether any intervention strategies (described next) had occurred spontaneously. This procedure provided a baseline of the (subsequent) independent variable (i.e., intervention). 


\section{Development of the Intervention and Training of the Intervention Agent}

The purpose of this component was to use assessment information about the transition context to develop an intervention to mitigate the impact of this variable on problem behavior within the natural ecology of a neighborhood school. The intervention package was designed to address the transitioning difficulties exhibited by the three children and consisted of several evidencebased strategies to modify environmental contexts. In this and the subsequent two studies, an array of treatment options was discussed and offered, for vetting, to each teacher who then selected the option that she felt represented the best "fit" for the relevant school environment (Albin, Lucyshyn, Horner, \& Flannery, 1996).

Presentation of a Visual Schedule. To ensure predictability in the child's day, we provided a visual schedule of the day's activities, highlighting the transitions, for each of the children. Several studies have noted the importance of using visual cues and organizational aides for children with autism spectrum disorders who are frequently described as visual learners (Dooley, Wilczenski, \& Torem, 2001; McClannahan \& Krantz, 1999; Quill, 1995). In the present study, the children were presented with three-ring binders containing pictures (for Joanne and Anna) and printed words (for Darrell) representing the child's daily activities in school that included all major subjects, minor subjects, lunch/recess, and therapies.

Presentation of Verbal Warning to Signal Impending Transition. Intervention agents were asked to provide a verbal warning (e.g., "Anna, we're finished now so we're going back to your classroom.") prior to the onset of the transition. Verbal warnings have been demonstrated to be a useful tool for enhancing predictability and decreasing challenging behavior when transitioning individuals with developmental disabilities from one activity to another (Flannery \& Horner, 1994; Tustin, 1995).

Altering the Environmental Arrangement. Environmental rearrangement, as defined by Davis and Fox (1999), involves manipulation of the physical or social composition of a classroom in order to effect behavior change. In the present study, Darrell's teacher noted that Darrell's difficulties with transition appeared to be attenuated by (a) briefer durations of transition (e.g., transitioning to a pull-out session in the nearby hallway was less difficult for him than transition to a distant therapy room) and (b) being accompanied by a preferred peer. Therefore, during the initial sessions of intervention, the OT session was conducted in the hallway just outside the classroom with two 
preferred peers (selected by Darrell). After several sessions, one peer was removed. Following additional sessions, the other peer was removed and Darrell participated in OT sessions alone in a nearby empty classroom. The final phase consisted of Darrell transitioning to the regular OT room that was located in a different (distant) wing of the school building.

Presentation of a 'What Did I Miss?' Cue Card. Children with autism have been found to respond negatively when asked to engage in an activity that is already in progress (Schmit, Alper, Raschke, \& Ryndak, 2000). For all three children in the present study, difficulties joining activities that had already begun, negatively impacted the children's ability to transition. Using a proactive cueing system to ameliorate problem behavior in children with autism has been documented to be an effective strategy (Mace, Shapiro, \& Mace, 1998; Tustin, 1995). Therefore, a 'What did I miss?' written cue card was given to each child prior to his/her returning to a classroom activity. This card acted as a visual prompt for the child to approach the teacher to ask what classroom activity had been missed and for the teacher to provide the relevant information.

Once the intervention package had been developed, we trained the intervention agents (for Darrell, his occupational therapist; for Joanne and Anna, their 1:1 aides). First, the investigator verbally explained the procedures to the intervention agent and then modeled the use of the strategies with the child for three sessions. Then, the intervention agent implemented the multicomponent intervention package with verbal feedback from the investigator until "performance to criteria" standards were met. The "performance to criteria" standards were defined as using the intervention components listed in the "intervention fidelity" checklist (described shortly) correctly for $100 \%$ of the transition routine across three consecutive sessions. Once these criteria were met, verbal feedback from the investigator was eliminated.

\section{Intervention Implementation}

The purpose of this component was to evaluate whether the intervention would result in a reduction in problem behavior and an increase in the percentage of the routine completed. During this phase, measures were collected for the use of each intervention component (independent variable integrity). Presentation of a visual schedule was defined as (a) providing the child with a visual schedule outlining the day's activities at the beginning of the day prior to the onset of any classroom activities, and (b) prior to the onset of each activity depicted on the outline. Presentation of a verbal warning was 
defined as presenting the child with a 5-min verbal warning (e.g., "Now we're going to the gym, Joanne") prior to leaving the classroom to attend the targeted activity (i.e., OT, PE, class). Environmental rearrangement (Darrell only) was defined as (a) gradually increasing the distance from the classroom to the new setting and (b) decreasing the number of preferred students (peers) accompanying the child with autism from the class to the new setting. Presentation of the 'What did I miss?' cue card was defined as providing the child with the visual cue card 2 minutes prior to the child's returning to a classroom activity.

Interrater Reliability. A binary reliability index was used to assess agreement on percentage of the transition steps completed and latency; that is, for each session, reliability was scored as either perfect agreement or no agreement. Agreement was defined as both observers recording the same number of transition steps completed; the same type of intervention components (e.g., if both raters indicated that the aide had begun a transition with a verbal warning, then agreement was scored for the use of warnings); latency measures that were within $5 \mathrm{sec}$ of one another; exact agreement on the number of untolerated and tolerated problem behaviors; agreement on the session duration (raters' durations were within $5 \mathrm{sec}$ of one another); and agreement on the reason for session termination (i.e., occurrence of problem behavior versus successful completion of the transition).

Darrell. Two observers independently (but concurrently) completed reliability checks for $33 \%$ (i.e., 1) of the baseline sessions and 37\% (i.e., 10) of the intervention sessions. Agreement was noted in $100 \%$ of the baseline sessions, and $90 \%$ of the intervention sessions.

Joanne. Two observers independently (but concurrently) completed reliability checks for $33 \%$ (i.e., 2) of the baseline sessions and 38\% (i.e., 9) of the intervention sessions. Agreement was noted in $84 \%$ of the baseline sessions, and $93 \%$ of the intervention sessions.

Anna. Two observers independently (but concurrently) completed reliability checks for $33 \%$ (i.e., 3) of the baseline sessions and $43 \%$ (i.e., 9) of the intervention sessions. Agreement was noted in $100 \%$ of the baseline sessions, and $96 \%$ of the intervention sessions.

\section{Intervention Fidelity}

An "intervention fidelity" checklist, based on the definitions of the independent variable described earlier, was developed to evaluate intervention integrity (Appendix A, top section). In 33\%-50\% of the sessions (for both 
baseline and intervention) for Darrell, Joanne, and Anna, the investigator and a graduate student in clinical psychology recorded whether each intervention component was correctly implemented by the intervention agent. That is, the observer(s) completed the intervention fidelity checklist, responding to "yes/ no" questions as to whether a specific component of the multicomponent intervention package was or was not used.

\section{Ancillary Measures of Social Validity}

Teachers and support staff were asked to complete measures of social validity for the independent variables at the end of intervention implementation and for the dependent variables prior to and at the end of intervention implementation. The social validity measure for the independent variable (IV) was a 2-item, 7-point Likert-type questionnaire (Carr et al., 1994) regarding the multicomponent intervention (shown in Appendix B). Specific questions addressed ease of strategy use and perceived helpfulness of the strategies. The social validity measure for the dependent variable (DV) was a three-item, 7-point Likert-type questionnaire (Carr \& Carlson, 1993) regarding the child's problem behavior (shown in Appendix C). Specific questions addressed the perceived severity of the child's problem behavior, whether the child was a danger to him/herself or others, and whether the child was a disruption to the setting.

\section{Results}

Intervention Fidelity. For each child, intervention fidelity checks were completed during each session in which interrater reliability was assessed.

Darrell. In baseline, $0 \%$ of the intervention components were recorded as having been implemented by the intervention agent. In intervention, $92 \%$ of the intervention components were implemented by the intervention agents.

Joanne. In baseline, $17 \%$ of the intervention components were implemented by the intervention agent. In intervention, $85 \%$ of the intervention components were implemented.

Anna. In baseline, $22 \%$ of the intervention components were implemented by the intervention agent. In intervention, $93 \%$ of the intervention components were implemented.

Percentage of Task Steps Completed. Percentage of transition steps completed for each participant is shown in Figure 1. In baseline, Darrell completed $0 \%$ of the steps that constituted the transition. However, in 


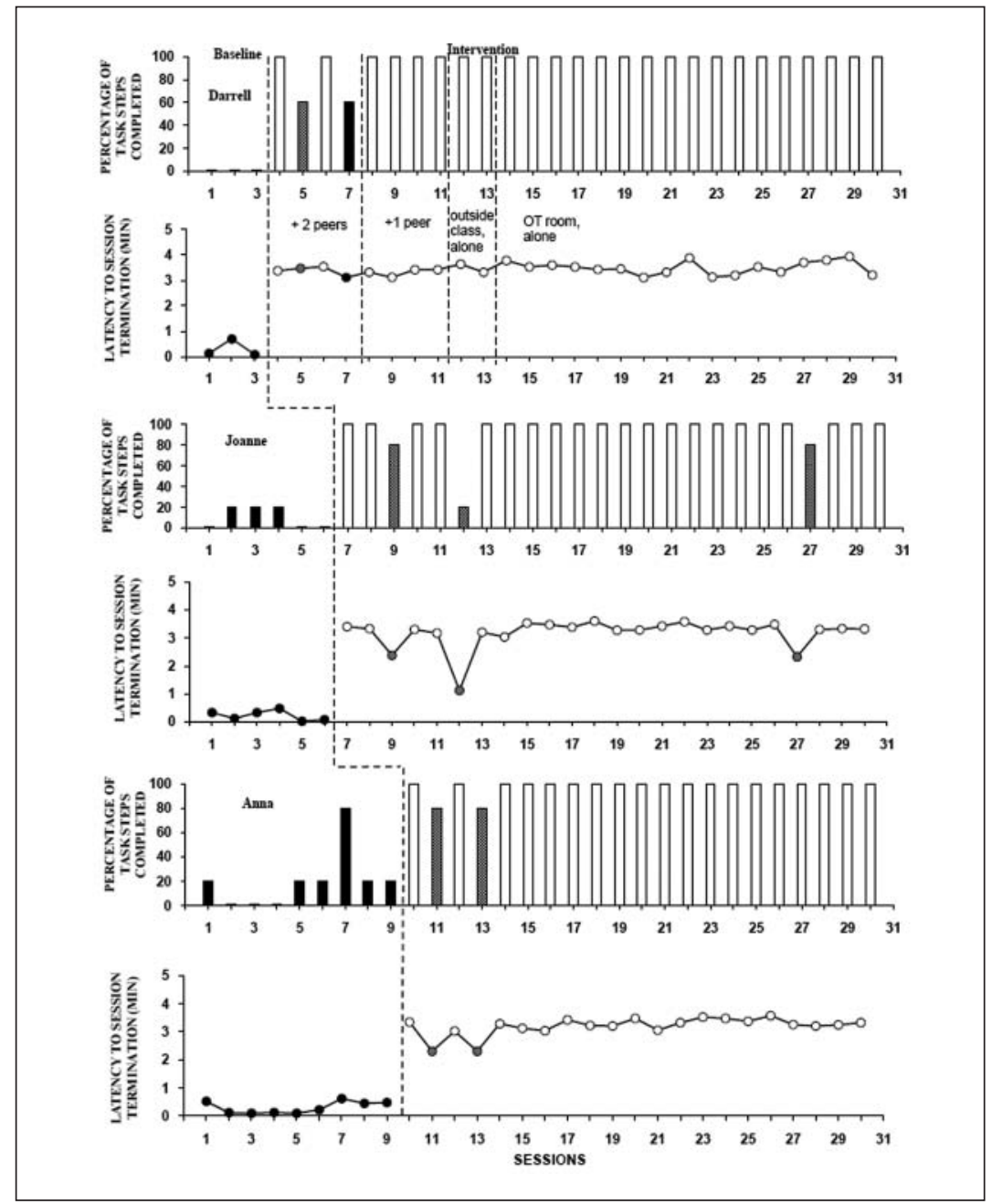

Figure I. Percentage of Task Steps Completed and Latency to Session Termination for Three Participants in the Baseline and Intervention Phases Related to Transitions as a Problem Context

Note: In addition, for Darrell, each phase of transitioning is indicated below the first graph. The solid black bars denote those session e to untolerated problem behavior. The gray bars denote those sessions terminated due to tolerated problem behavior. The open bars denote those sessions in which the task was successfully completed without the need to terminate due to problem behavior. 
intervention, he completed $100 \%$ of the steps for 25 out of 27 sessions, and $60 \%$ of the steps for the remaining 2 sessions. In baseline, Joanne completed a mean of $10 \%$ of the steps. However, in intervention she completed $100 \%$ of the steps for 21 out of 24 sessions, $80 \%$ of the steps for 2 sessions, and $20 \%$ of the steps for the remaining session. In baseline, Anna completed a mean of $18 \%$ of the steps. However, in intervention she completed $100 \%$ of the steps for 18 out of 20 sessions, and $80 \%$ of the steps for the remaining 2 sessions.

Latency to Session Termination. Figure 1 also presents data on the amount of time that elapsed before problem behavior or successful session termination occurred (latency) for the three participants. For Darrell, mean latency to session termination in baseline due to the onset of problem behavior was $18 \mathrm{~s}$. During intervention, his latency to successful session termination (i.e., no problem behavior) was $3 \mathrm{~min} 30 \mathrm{~s}$. For Joanne, mean latency to problem behavior was $23 \mathrm{~s}$ in baseline. During intervention, her latency to successful session termination was 3 min $21 \mathrm{~s}$. Finally, for Anna, mean latency to problem behavior was $18 \mathrm{~s}$ in baseline. During intervention, her latency to successful session termination was 3 min $17 \mathrm{~s}$.

Number of Sessions Terminated. As shown in Figure 1, sessions could be terminated because of the presence of untolerated problem behavior (solid black bars), tolerated problem behavior (gray bars), or successful completion of the transition in the absence of problem behavior (open bars). For each child in baseline, all sessions were terminated due to the presence of problem behavior. Following intervention for Darrell, only 2 out of 27 sessions were terminated (one due to untolerated problem behavior and one due to tolerated problem behavior). Thus, 25 sessions were terminated because the transition was successfully completed in the absence of problem behavior. For Joanne, only 3 out of 24 sessions were terminated (due to three sessions associated with tolerated problem behavior) and, for Anna, only 2 of the 21 intervention sessions were terminated (due to tolerated problem behavior).

Ancillary Measures of Social Validity. The social validity data for the intervention (IV) are shown in Table 1, and the data for the impact of the intervention on problem behavior (DV) are shown in Table 2. As can be seen in Table 1 (top section), across the three children for Item 1 (ease of strategy use), the mean was 7 , indicating that the intervention agents reported the highest level of ease of strategy use. Across the three children for Item 2 (helpfulness of strategies), the mean was 7, indicating that the intervention agents reported the highest level of helpfulness. As can be seen in Table 2 
Table I. Social Validity Data for the IV

\begin{tabular}{llcc}
\hline Context & Participant & $\begin{array}{c}\text { Ease of } \\
\text { Strategy Use }\end{array}$ & $\begin{array}{c}\text { Helpfulness } \\
\text { of Strategies }\end{array}$ \\
\hline Transitions & Darrell & 7 & 7 \\
& Joanne & 7 & 7 \\
\multirow{5}{*}{ Termination of preferred activity } & Anna & 7 & 7 \\
& Brian & 7 & 7 \\
& Tanner & 6 & 7 \\
Presence of feared stimulus & Tim & 7 & 7 \\
& Danielle & 7 & 7 \\
& Robert & 7 & 7 \\
\hline
\end{tabular}

IV = independent variable.

Note: Each question was rated on a 7-point scale, with 7 representing strongly agree, 4 representing somewhat agree, and I representing strongly disagree.

Table 2. Social Validity Data for the DV

\begin{tabular}{|c|c|c|c|c|c|c|c|}
\hline \multirow[b]{2}{*}{ Context } & \multirow[b]{2}{*}{ Participant } & \multicolumn{2}{|c|}{$\begin{array}{l}\text { Severity of } \\
\text { Problem } \\
\text { Behavior }\end{array}$} & \multicolumn{2}{|c|}{$\begin{array}{l}\text { Danger to } \\
\text { Self or } \\
\text { Others }\end{array}$} & \multicolumn{2}{|c|}{$\begin{array}{c}\text { Disruption } \\
\text { to } \\
\text { Setting }\end{array}$} \\
\hline & & Pre & Post & Pre & Post & Pre & Post \\
\hline \multirow[t]{3}{*}{ Transitions } & Darrell & 7 & 1 & 6 & I & 7 & 2 \\
\hline & Joanne & 5 & 2 & 5 & I & 5 & 2 \\
\hline & Anna & 5 & I & 6 & I & 6 & 1 \\
\hline Termination of Preferred & Brian & 6 & 2 & 4 & I & 5 & I \\
\hline \multirow[t]{2}{*}{ Activity } & Tanner & 7 & 3 & 5 & I & 7 & 2 \\
\hline & Tim & 6 & I & 2 & I & 5 & 1 \\
\hline \multirow{3}{*}{$\begin{array}{l}\text { Presence of Feared } \\
\text { Stimulus }\end{array}$} & Danielle & 5 & 1 & 3 & I & 5 & I \\
\hline & Robert & 7 & 2 & I & I & 7 & I \\
\hline & Joanne & 7 & 2 & 5 & 2 & 6 & 2 \\
\hline
\end{tabular}

DV = dependent variable.

Note: Each tion was rated on a 7-point scale, with 7 representing strongly agree, 4 representing somewhat agree, and I representing strongly disagree.

(top section), the intervention agents indicated that, following intervention, the severity, danger, and impact of problem behavior declined to very low levels (mean $=1.3$; range $=1-2$ ) in contrast to preintervention (i.e., baseline), where the levels were high $($ mean $=5.8$; range $=5-7$ ). 


\section{Study 2:Termination of a Preferred Activity as a Context for Problem Behavior}

\section{Method}

Participant and Context Selection. The procedures described in Study 1 for participant and context selection were repeated in Study 2 for a new group of families. This process resulted in the selection of three boys with autism, ranging in age from 6 to 7 years old, for whom mothers nominated "termination of preferred activity in school" as the context most likely to be associated with problem behavior. The postassessment interview with the children's teachers confirmed that all three boys were most likely to exhibit problem behavior in the context initially identified by the mothers.

Participant I: Brian. Brian was a 6-year-old boy diagnosed with autism (Full Scale IQ $=65$, Leiter International Performance Scale, Revised) who was in a regular kindergarten class where he received the support of a fulltime aide. During the postassessment interview with Brian's mother, termination of preferred activities was identified as a consistent trigger for his problem behavior in school. An additional postassessment interview was conducted with Brian's teacher, who stated that the period following highly preferred "free choice" activities in the classroom was the most difficult for him, as he often screamed and tantrummed when he was instructed to put away his painting supplies (termination of free choice) in order to begin the classwide circle time activity.

Participant 2:Tanner. Tanner was a 6-year-old boy diagnosed with autism (Full Scale IQ $=72$, Leiter International Performance Scale, Revised) who was in a self-contained class where he received the support of a full-time aide. Based on the postassessment interview conducted with his mother, significant problem behavior was noted during the school day when a preferred activity ended. The postassessment interview was also conducted with his classroom teacher, who described significant problem behavior when Tanner was instructed to begin his daily tabletop activities (nonpreferred activity). Specifically, Tanner engaged in problem behavior (i.e., screaming, dropping to the floor, throwing items) when instructed to shut off a videotaped movie (preferred activity) in order to begin the work activity.

Participant 3:Tim. Tim was a 7-year-old boy diagnosed with autism (Full Scale IQ $=53$, Wechsler Intelligence Scale for Children, Fourth Edition), who was in a self-contained class for students with autism, where he received the support of a full-time aide. The postassessment interview with his mother revealed that his greatest difficulties during the school day occurred when he was asked to leave a preferred activity. His teacher noted similar concerns 
during the postassessment interview, specifying the period when Tim was asked to stop playing on the computer to begin working at his desk as especially problematic. During those times, Tim screamed, drop to the floor, and displayed aggressive behaviors (i.e., squeezing the teacher's arm). The teacher stated that to prevent these behavioral episodes, she no longer permitted Tim to use the computer in the classroom.

\section{Baseline Observations}

During baseline, the problematic context was observed by the investigator and a second observer, a graduate student in clinical psychology, to confirm presence of problem behavior. As described in Study 1, a task analysis was developed to evaluate each student's progress following termination of the preferred activity. Steps for successful completion of the classroom routine following the teacher's instruction to terminate the preferred activity were defined as: (a) the child stopped engaging in the preferred activity; (b) the child moved away from the preferred activity in the direction of the next (i.e., nonpreferred) activity; (c) the child sat down to begin the nonpreferred activity; (d) the child engaged in the nonpreferred activity for at least 3 minutes, indicating acceptance of that activity.

For Brian, baseline data were collected during the morning routine in the classroom, where the students were given a "free choice" activity, and Brian consistently selected the painting activity. Once the activity ended, the students were told by the teacher to clean up and sit on the carpet in order to begin "circle time." For Tanner, baseline data were collected in the classroom, where his 1:1 aide told Tanner that "movie time" had ended and it was now time to work. For Tim, baseline data were collected in the classroom, where Tim's consultant/teacher prompted him to turn off the computer and go back to his seat to work.

\section{Response Recording}

Data collection procedures were identical to those outlined in Study 1.

\section{Development of the Intervention and Training of the Intervention Agent}

The investigator devised a relevant intervention based on an empirically supported intervention strategy to address the children's difficulties when a preferred activity ended or was no longer possible. 
Countdown Cards. The literature on children with developmental disabilities has demonstrated that providing signaled (i.e., predictable) events may prevent the occurrence of problem behavior (Flannery \& Horner, 1994). Therefore, in order to "signal" ending of a preferred task for the three children in the present study, countdown cards on a key ring (marked as 5, 4, 3, 2 , and 1 , respectively) were visually and verbally presented to each child by the intervention agent after the teacher request to terminate the preferred task and initiate the next activity.

Once the intervention was developed, we trained the intervention agents to administer the intervention. For Brian and Tanner, their 1:1 aides were trained in the intervention. For Tim, the special education consultant-teacher was trained. Training procedures were identical to those outlined in Study 1.

\section{Intervention Implementation}

Correct presentation of the countdown cards by the intervention agent was defined as presenting the child with the countdown cards, in order, within 2 min of the teacher request to terminate the preferred activity and initiate the new activity.

Interrater Reliability. Using the same procedure as in Study 1, the investigator and a graduate student in clinical psychology collected reliability data on the primary independent and dependent variables.

Brian. Two observers independently (but concurrently) completed reliability checks for $33 \%$ (i.e., 1) of the baseline sessions and $41 \%$ (i.e., 11) of the intervention sessions. Agreement was noted in $100 \%$ of the baseline sessions, and $100 \%$ of the intervention sessions.

Tanner. Two observers independently (but concurrently) completed reliability checks for 50\% (i.e., 3) of the baseline sessions and 38\% (i.e., 9) of the intervention sessions. Agreement was noted in $100 \%$ of the baseline sessions, and $100 \%$ of the intervention sessions.

Tim. Two observers independently (but concurrently) completed reliability checks for $44 \%$ (i.e., 9) of the baseline sessions and 33\% (i.e., 7) of the intervention sessions. Agreement was noted in $100 \%$ of the baseline sessions, and $100 \%$ of the intervention sessions.

\section{Intervention Fidelity}

Using the procedure described in Study 1, an "intervention fidelity" checklist (Appendix A, middle section) was developed to confirm the use of the intervention. In $33 \%-50 \%$ of the baseline and intervention 
sessions, two observers recorded whether or not the intervention package was implemented.

\section{Ancillary Measures of Social Validity}

These measures were identical to those described in Study 1.

\section{Results}

Intervention Fidelity. For each child, intervention fidelity checks were completed during each session in which interrater reliability was assessed.

Brian. In baseline, $0 \%$ of the intervention components were recorded as having been implemented by the intervention agent. In intervention, $100 \%$ of the intervention components were implemented by the intervention agent.

Tanner. In baseline, $0 \%$ of the intervention components were recorded as having been implemented by the intervention agent. In intervention, $89 \%$ of the intervention components were implemented by the intervention agent.

Tim. In baseline, $0 \%$ of the intervention components were recorded as having been implemented by the intervention agent. In intervention, $100 \%$ of the intervention components were implemented by the intervention agent. Percentage of Task Steps Completed. Percentage of the steps completed for each participant is shown in Figure 2. In baseline, Brian completed $0 \%$ of the steps that constituted the routine. However, in intervention, he completed $100 \%$ of the steps for 26 out of 27 sessions, and $25 \%$ of the steps for the remaining session. In baseline, Tanner completed $0 \%$ of the steps. However, in intervention, he completed $100 \%$ of the steps for 22 out of 24 sessions, and $25 \%$ of the steps for the remaining 2 sessions. In baseline, Tim completed $0 \%$ of the steps. However, in intervention, he completed $100 \%$ of the steps for 20 out of 20 sessions.

Latency to Session Termination. Figure 2 also presents data on the amount of time that elapsed before problem behavior or successful session termination occurred (latency) for the three participants. For Brian, mean latency to session termination in baseline due to the onset of problem behavior was $19 \mathrm{~s}$. During intervention, his latency to successful session termination was 3 min $12 \mathrm{~s}$. For Tanner, mean latency to session termination in baseline due to the onset of problem behavior was $34 \mathrm{~s}$. During intervention, his latency to successful session termination was 3 min $8 \mathrm{~s}$. Finally, for Tim, mean latency to session termination in baseline due to the onset of problem behavior was $17 \mathrm{~s}$. During intervention, his latency to successful session termination was $3 \min 25 \mathrm{~s}$. 

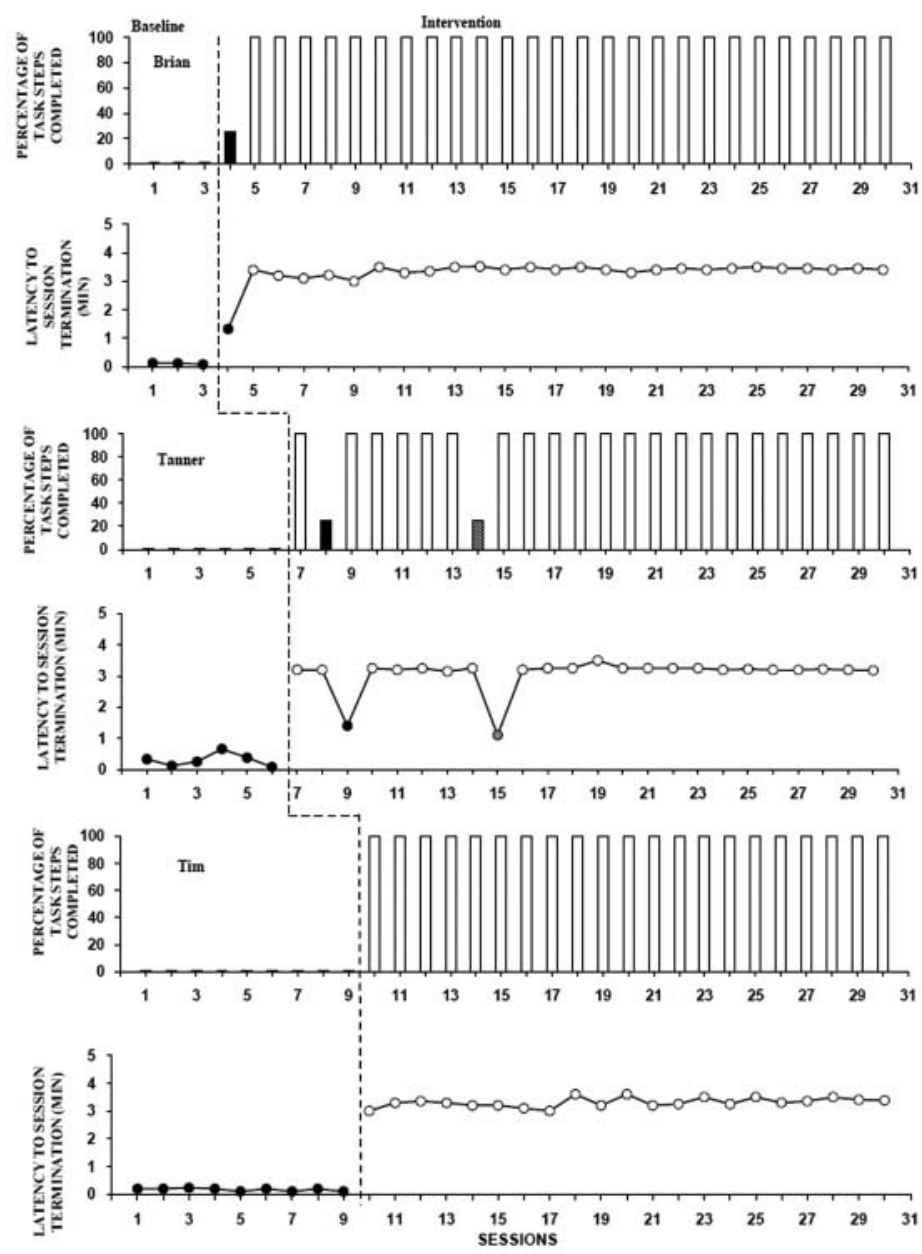

Figure 2. Percentage of task steps completed and latency to session termination for three participants during the baseline and intervention phases related to termination of a preferred activity as a problem context

Note:The solid black bars denote those sessions terminated due to untolerated problem behavior. The gray bars denote those sessions terminated due to tolerated problem behavior. The open bars denote those sessions in which the task was successfully completed without the need to terminate due to problem behavior. 
Number of Sessions Terminated. As shown in Figure 2, for each child in baseline, all sessions were terminated due to the presence of problem behavior. Following intervention for Brian, only 1 out of 27 sessions was terminated (due to untolerated problem behavior). For Tanner, only 2 out of 24 sessions were terminated (one due to untolerated problem behavior, and one due to tolerated problem behavior). For Tim, none of the intervention sessions was terminated due to problem behavior.

Ancillary Measures of Social Validity. The social validity data for the intervention (IV) are shown in Table 1, and the data for the impact of the intervention on problem behavior (DV) are shown in Table 2. As can be seen in Table 1 (middle section), across the three children for Item 1 (ease of strategy use), the mean was 6.7, indicating that the intervention agents reported a very high level of ease of strategy use. Across the three children for Item 2 (helpfulness of strategies), the mean was 7, indicating that the intervention agents reported the highest level of helpfulness. As can be seen in Table 2 (middle section), the intervention agents indicated that, following intervention, the severity, danger, and impact of problem behavior declined to very low levels (mean $=1.4$; range $=1-3$ ) in contrast to preintervention (i.e., baseline), where the levels were high ( mean $=5.2$; range $=2-7$ ).

\section{Study 3:The Presence of a Feared Stimulus as a Context for Problem Behavior}

\section{Method}

Participant and Context Selection. Procedures described in Study 1 for participant and context selection were repeated in Study 3 for a new group of families. This process resulted in the selection of three children with autism, ranging in age from 5 to 7 years old, for whom families nominated "the presence of a feared stimulus in school" as the context most likely to be associated with problem behavior. The postassessment interview with the children's teachers confirmed that all three children were most likely to exhibit problem behavior in the context initially identified by the parents. Although fear can be difficult to assess in young children with autism, the teachers of the three children noted that each child, when confronted with the identified problem situation, reliably exhibited one or more nonverbal behaviors consistent with fear: startle response, gasping, hyperventilation, trembling hands, shielding face with hands, closing eyes and turning away from the stimulus, and wincing. 
Participant I: Danielle. Danielle was a 6-year-old girl diagnosed with Asperger's Syndrome (Full Scale IQ $=108$, Wechsler Intelligence Scale for Children, Fourth Edition) who was placed in an inclusion kindergarten classroom where she received instruction with 15 typical peers as well as two peers with other disabilities. During the postassessment interview, both Danielle's mother and her kindergarten teacher indicated that Danielle was most likely to exhibit problem behavior in school when she was in the presence of a feared stimulus. The teacher reported that Danielle frequently engaged in problem behavior (e.g., screaming, crying) during whole group reading activities, where the children were reading stories that contained specific onomatopoeic sounds (e.g., sneezing: "a choo," and "huff and puff").

Participant 2: Robert. Robert was a 7-year-old boy diagnosed with Autism Spectrum Disorder (Full Scale IQ = 77, Wechsler Intelligence Scale for Children, Fourth Edition) who attended a regular first-grade class with the support of a 1:1 aide. During the postassessment interview, Robert's mother stated that her son was most likely to exhibit problem behavior in the presence of a feared stimulus in school. His teacher noted similar difficulties, stating that Robert had the greatest difficulty during math, where the students were presented with textbook materials that contained pictures of sea creatures and ocean scenery (e.g., fish, shark, starfish, shells). Specifically, during those math activities that contained materials with sea creatures on them, Robert would often scream and display aggressive behaviors (i.e., pushing) in response to the feared stimulus.

Participant 3: Joanne. Joanne had already participated in Study 1. During the postassessment interview, Joanne's mother noted that Joanne also displayed significant levels of problem behavior in response to a feared stimulus. Her teacher noted similar difficulties during indoor recess, as Joanne feared the videos presented during indoor recess. Specifically, Joanne feared the "Arthur" video collection, a brief set of videos about a talking aardvark. During lunch on those days when the children were informed that there would be indoor recess, Joanne immediately began screaming and dropping to the floor. Due to these behaviors, Joanne would not attend the indoor recess activity in the auditorium, and would be taken to the classroom with her 1:1 aide instead.

\section{Baseline Observations}

During baseline, the problematic context was observed by the investigator and a second observer, a graduate student in clinical psychology, to confirm the presence of problem behavior. As described in Study 1, a task analysis 
was developed to evaluate each student's progress when they were in the presence of a feared stimulus. Steps for successful completion of the classroom routine following the teacher's instruction to begin the activity were defined as: (a) the child began the selected activity, and (b) the child engaged in the selected activity for at least 3 minutes, indicating acceptance of that activity.

For Danielle, baseline data were collected during a pull-out reading activity that Danielle would attend on a weekly basis with her peers and special education teacher. For Robert, baseline data were collected in the classroom, where Robert's 1:1 aide would present him with a math worksheet that had ocean scenery as its background. For Joanne, baseline data were collected in the lunchroom, when Joanne's class was informed that they would be seeing a movie (from the "Arthur" series) during the indoor recess period.

\section{Response Recording}

Data collection procedures were identical to those outlined in Study 1.

\section{Development of the Intervention and Training of the Intervention Agent}

The investigator devised a relevant intervention based on an empirically supported intervention strategy to address the children's difficulties when presented with a feared stimulus.

Choice. Choice-making has been documented in the developmental disabilities literature as a highly effective strategy for eliminating problem behavior (Bambara, Koger, Katzer, \& Davenport, 1995; Brown, Belz, Corsi, \& Wenig, 1993; Cole \& Levinson, 2002). Through participation in the choice-making process, a child can select preferred stimuli and avoid nonpreferred stimuli (Dunlap et al., 1991). In the present study, all three children were given choices between the feared stimulus and an alternative item matched in content with the feared stimulus but not, itself, evoking fear. If the child verbally requested the preferred item over the feared item, he/she was then given access to it.

Danielle. As previously mentioned, Danielle's feared stimuli were reading materials that contained specific, onomatopoeic sounds. Therefore, during the small group reading session, Danielle was presented with a choice of reading materials that were preselected by her special education teacher. For example, Danielle would be presented with two books, The Three Little Pigs (which contained the "huff" and "puff" noises), and another book that was 
matched for reading level, but did not contain any onomatopoeic sounds (e.g., If You Give a Mouse a Cookie). She was then instructed to select the one that she would like to have read by the teacher.

Robert. Robert's fears involved pictures of sea creatures that appeared on his math worksheets. Therefore, during math, Robert was provided with a choice between worksheets that were matched for content, with one worksheet containing a picture of a sea creature as the background, and other worksheets containing pictures of pencils, land animals, and trains as the background. Because of limited language skills (i.e., Robert could read but not talk well), he was provided with a choice prompt card, that was labeled with "I want this one." Robert was presented with the card and told to select one of the worksheets by placing the card on top of the worksheet he wanted.

Joanne. Joanne was observed during the indoor recess period, where she exhibited fear in response to the Arthur movie series that was often shown to her class. The intervention for Joanne involved having Joanne select two of three videos prior to the indoor recess period with her 1:1 aide (with only one video being from the Arthur series, and the others involving Disney characters and the Rugrats video series). Her 1:1 aide would then give the two selected videos to the recess teacher who would then have the students collectively vote on which video they would watch.

Once the intervention had been developed, we trained the intervention agents to carry out the intervention. For Danielle, her special education teacher was the intervention agent. For Robert and Joanne, the 1:1 aides were trained to implement the intervention. The training procedures were identical to those outlined in Study 1.

\section{Intervention Implementation}

Correct presentation of the intervention package by the intervention agent was defined as presenting the child with a choice between the feared stimulus and an alternative stimulus (or alternative stimuli) that were matched with the feared stimulus relative to generic content category (i.e., a book with a book; a worksheet with a worksheet; a film with a film).

Interrater Reliability. Using the same procedure as in Study 1, the investigator and a graduate student in clinical psychology collected reliability data on the primary independent and dependent variables.

Danielle. Two observers independently (but concurrently) completed reliability checks for 33\% (i.e., 1) of the baseline sessions and 33\% (i.e., 9) of the intervention sessions. Agreement was noted in $100 \%$ of the baseline sessions, and $94 \%$ of the intervention sessions. 
Robert. Two observers independently (but concurrently) completed reliability checks for $50 \%$ (i.e., 3) of the baseline sessions and 33\% (i.e., 8) of the intervention sessions. Agreement was noted in $100 \%$ of the baseline sessions, and $88 \%$ of the intervention sessions.

Joanne. Two observers independently (but concurrently) completed reliability checks for 33\% (i.e., 3) of the baseline sessions and 38\% (i.e., 8) of the intervention sessions. Agreement was noted in $100 \%$ of the baseline sessions, and $100 \%$ of the intervention sessions.

\section{Intervention Fidelity}

Using the procedure described in Study 1, an "intervention fidelity" checklist (Appendix A, bottom section) was developed to evaluate intervention integrity. In $33 \%-50 \%$ of the baseline and intervention sessions, two observers recorded whether or not each component of the intervention package was implemented.

\section{Ancillary Measures of Social Validity}

These measures were identical to those described in Study 1.

\section{Results}

Intervention Fidelity. For each child, intervention fidelity checks were completed during each session in which interrater reliability was assessed.

Danielle. In baseline, $0 \%$ of the intervention components were recorded as having been implemented by the intervention agent. In intervention, $100 \%$ of the intervention components were implemented by the intervention agent.

Robert. In baseline, $0 \%$ of the intervention components were recorded as having been implemented by the intervention agent. In intervention, $94 \%$ of the intervention components were implemented by the intervention agent.

Joanne. In baseline, $0 \%$ of the intervention components were recorded as having been implemented by the intervention agent. In intervention, $100 \%$ of the intervention components were implemented by the intervention agent. Percentage of Task Steps Completed. Percentage of steps completed for each participant is shown in Figure 3. In baseline, Danielle completed 0\% of the steps that constituted the routine. However, in intervention she completed $100 \%$ of the steps for 27 out of 27 sessions. In baseline, Robert completed $0 \%$ of the steps that constituted the routine. However, in intervention he completed $100 \%$ of the steps for 23 out of 24 sessions, and $50 \%$ of the steps for 

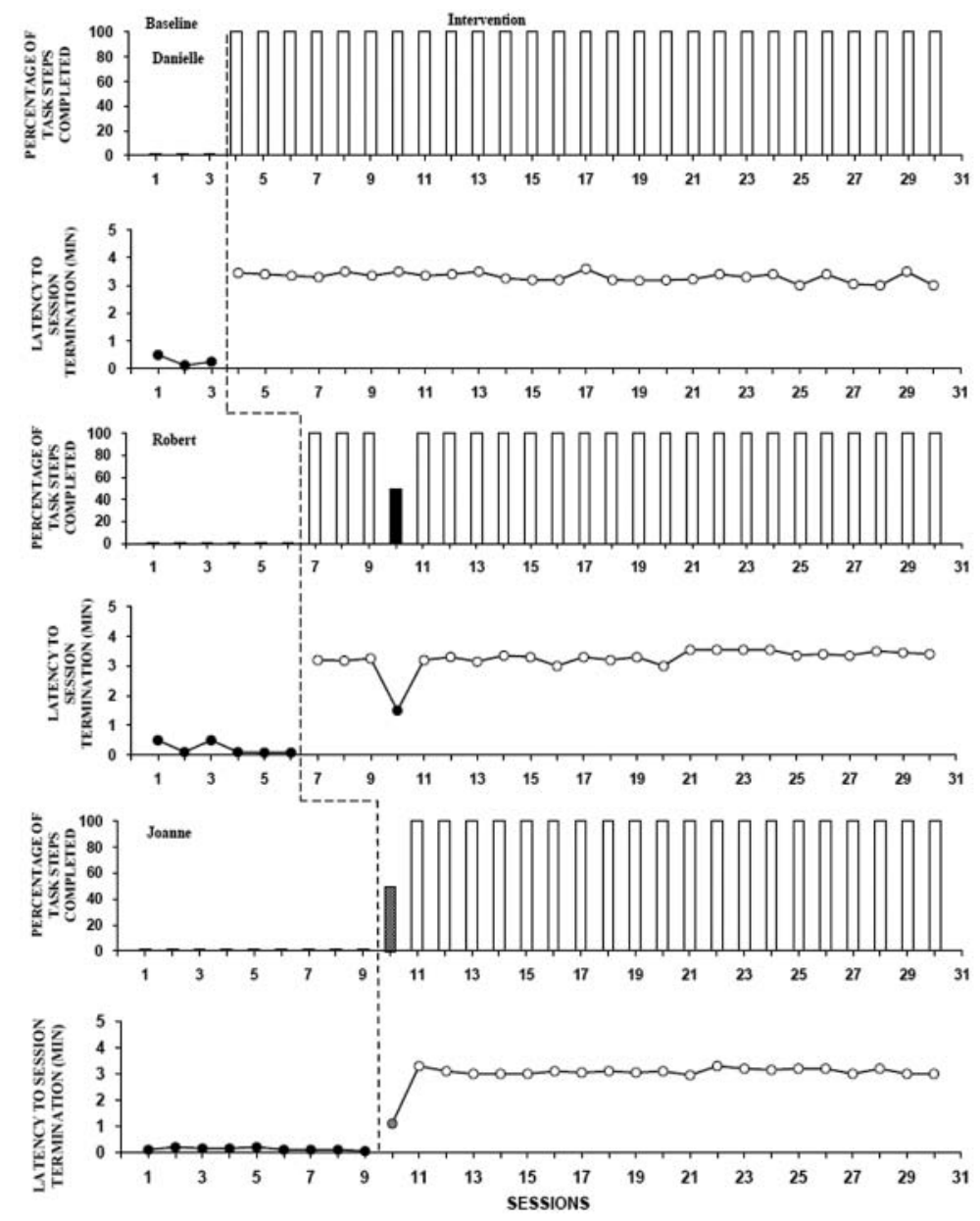

Figure 3. Percentage of Task Steps Completed and Latency to Session Termination for Three Participants During the Baseline and Intervention Phases Related to Presence of Feared Stimuli as a Problem Context

Note:The solid black bars denote those sessions terminated due to untolerated problem behavior. The gray bars denote those sessions terminated due to tolerated problem behavior. The open bars denote those sessions in which the social activity was successfully completed without the need to terminate due to problem behavior. 
the remaining session. In baseline, Joanne completed $0 \%$ of the steps that constituted the routine. However, in intervention she completed $100 \%$ of the steps for 19 out of 20 sessions, and $50 \%$ of the steps for the remaining session.

Latency to Session Termination. Figure 3 also presents data on the amount of time that elapsed before problem behavior or successful session termination occurred (latency) for the three participants. For Danielle, mean latency to session termination in baseline due to the onset of problem behavior was 29 s. During intervention, her latency to successful session termination was $3 \mathrm{~min} 31 \mathrm{~s}$. For Robert, mean latency to session termination in baseline due to the onset of problem behavior was $28 \mathrm{~s}$. During intervention, his latency to successful session termination was 3 min $23 \mathrm{~s}$. Finally, for Joanne, mean latency to session termination in baseline due to the onset of problem behavior was $17 \mathrm{~s}$. During intervention, her latency to successful session termination was 3 min $19 \mathrm{~s}$.

Number of Sessions Terminated. Sessions as shown in Figure 3, for each child in baseline, all sessions were terminated due to the presence of problem behavior. Following intervention for Danielle, none of the 27 sessions were terminated due to problem behavior. For Robert, only 1 out of 24 sessions was terminated (due to untolerated problem behavior), and for Joanne, only 1 out of 21 sessions was terminated (due to tolerated problem behavior).

Ancillary Measures of Social Validity. Social validity data for the intervention (IV) are shown in Table 1, and the data for the impact of the intervention on problem behavior (DV) are shown in Table 2. As can be seen in Table 1 (bottom section), across the three children for Item 1 (ease of strategy use), the mean was 6.7, indicating that the intervention agents reported a very high level of ease of strategy use. Across the three children for Item 2 (helpfulness of strategies), the mean was 7, indicating that the intervention agents reported the highest level of helpfulness. As can be seen in Table 2 (bottom section), the intervention agents indicated that, following intervention, the severity, danger, and impact of problem behavior declined to very low levels $($ mean $=$ 1.4 ; range $=1-2$ ) in contrast to preintervention (i.e., baseline), where the levels were high $($ mean $=5.1$; range $=1-7)$.

\section{General Discussion}

In a series of three studies, a context-based model of assessment and intervention for problem behavior in children with autism was implemented and evaluated. All eight children who participated showed substantial improvements following intervention. Specifically, their inability to complete 
common school routines in baseline (short latency to problem behavior) was replaced, during intervention, with high rates of completion of routines due to the near total elimination of problem behavior.

\section{A Model for Context-Based Mechanisms of Problem Behavior Control}

Problem contexts produce problem behavior. Therefore, by altering the problem context, we may be able to reduce or eliminate the problem behavior. As noted earlier, context variables consist of antecedent discriminative stimuli and setting events. A given context variable can function as either type of antecedent. Thus, teasing, for example, could function as either a discriminative stimulus or a setting event. In illustration, if a boy is teased by his peers and aggresses against them, then the teasing may stop. In this instance, teasing is functioning as a discriminative stimulus that directly triggers aggressive behavior. Alternatively, if the boy were teased earlier in the day and then given a task demand by his teacher much later in the day, he may aggress against the teacher, and the teacher may respond by removing the task. In this instance, teasing is functioning as a setting event that increases the aversiveness of the task, making aggressive behavior more likely in the presence of the discriminative stimulus (i.e., the task demand). It may also be the case that many interventions function as setting events that countermand the effects of these discriminative stimuli, thereby facilitating the reduction of problem behavior.

In what follows, we will use the model, just articulated, to discuss plausible mechanisms related to the control of problem behavior by focusing on one child from each of the three studies as an illustrative example. In all three studies, it is plausible that the primary context variables that triggered problem behavior functioned as discriminative stimuli for such behavior and that some elements of the intervention, described later, functioned as setting events to attenuate the influence of these discriminative stimuli.

Study I: Darrell. Recall that Darrell's mother and teacher reported that he was most likely to exhibit problem behavior when asked to transition from the classroom to the OT room. At the start of the school year, the transition demand (e.g., "Darrell, it's time for OT") typically elicited verbal complaints from Darrell (e.g., "I don't like OT"), but no problem behavior. That is, he was initially able to leave the classroom and enter the OT room without incident. However, over time, the therapist introduced a series of difficult fine-motor tasks (i.e., writing) during OT. These tasks would trigger problem behavior, with Darrell dropping to the floor and engaging in self-injurious 
behavior. Over time, then, the transition demand (e.g., "Darrell, it's time for OT") reliably predicted subsequent aversive stimuli (i.e., the writing tasks) that themselves were discriminative for problem behavior. Functionally, then, the transition demand became a conditioned aversive discriminative stimulus (by virtue of its being paired reliably with the aversive writing task). Thus, self-injury that occurred in response to the transition demand had the effect not only of avoiding movement to the OT room, but also resulted in avoidance of having to participate in the writing tasks that were subsequently required in that room. In this manner, the transition demand came to function as a discriminative stimulus that triggered self-injury that, in turn, was negatively reinforced (strengthened) through subsequent successful avoidance of having to engage in the aversive writing task.

Study 2: Brian. Recall that Brian's mother and teacher reported that he was most likely to exhibit problem behavior when he was instructed to put away his painting supplies (termination of the "free choice" activity) in order to begin the classwide "circle time" activity. Whenever Brian was presented with the demand to put away his painting supplies, he engaged in problem behavior. Intermittently, such behavior caused the teacher to withdraw her demand that Brian put away his painting supplies. In other words, problem behavior was reinforced by producing continued access to the highly preferred "free choice" activities. Thus, problem behavior, in response to the teacher demand that free choice activities be terminated, was positively reinforced, on an intermittent schedule. Also, it is likely that the behavior was negatively reinforced in that it had the effect of avoiding the circle time activity that the teacher characterized as being highly aversive for Brian. In this manner, the demand to terminate a preferred activity came to function as a discriminative stimulus for problem behavior.

Study 3: Danielle. Recall that Danielle's mother and teacher reported that she was most likely to exhibit problem behavior during reading activities in which the children read stories that contained specific sounds that evoked fear (e.g., a sneezing sound). Danielle's subsequent screaming and crying in response to the idiosyncratic feared stimulus (e.g., the sneezing sound) would frequently cause the teacher to terminate the particular reading activity. Thus, screaming in the presence of the feared stimulus was negatively reinforced through termination of that stimulus. In this manner, the demand to read a story containing the feared stimulus came to function as a discriminative stimulus for problem behavior. 


\section{A Model for Context-Based Mechanisms of Intervention Effectiveness}

Plausibly, each context was associated with aversive stimuli that triggered problem behavior that, in turn, had the effect of minimizing (avoiding) the aversive aspects of the identified context. The logic of intervention, therefore, was to alter the context in ways that minimized the aversive stimuli, thereby reducing the motivation for problem behavior. For example, in Study 1 , the introduction of visual schedules, verbal warnings, preferred peers, and "What did I miss?" cards likely functioned to reduce the aversiveness inherent in unpredictable transitions. A similar strategy in Study 2, namely, the introduction of countdown cards, likely reduced the aversiveness inherent in the typically sudden and unpredictable cessation of preferred activities and the movement to nonpreferred activities. In essence, for Studies 1 and 2, the intervention strategies may have been functioning as setting events, diminishing the aversiveness of the problematic contexts, thereby undermining the negative reinforcement that had previously maintained problem behavior. In other words, as noted previously, the likely functional mechanism underlying the effectiveness of intervention was that of an establishing (motivating) operation. Finally, in Study 3, allowing the children to choose among academic stimuli gave them the opportunity to avoid the feared stimulus without compromising the instructional goal of the task at hand. Essentially, a discriminative stimulus for appropriate behavior replaced a discriminative stimulus for problem behavior. In sum, across all three studies, intervention strategies relevant to discriminative stimulus effects or setting event effects altered the features of the problematic contexts, making unnecessary the problem behavior that had functioned to avoid those contexts.

\section{Ecological and Social Validity}

There is a rich and longstanding tradition of assessment and intervention with problem behavior in the context of highly controlled laboratory or analog situations that simulate aspects of the natural environment (Iwata et al., 1982; Scotti, Evans, Meyer, \& Walker, 1991). This research literature has been instrumental in demonstrating internal validity (cause-effect relationships) as well as providing important guidelines for developing accurate assessment and generic intervention strategies. A key question that has emerged from this literature concerns the degree to which the information generated is transferable to real-world situations, that is, whether the assessment and intervention strategies possess ecological validity (Carr et al., 
2002). Data produced across the three studies described suggest that contextbased strategies are robust with respect to several critical dimensions of ecological validity. Specifically, they are applicable in natural venues (e.g., classrooms, the OT room, the gym) by natural intervention agents (e.g., teachers, support staff, occupational therapists) within natural routines (e.g., indoor recess, circle time, reading).

\section{Breadth of Effects: Limitations and Future Research Opportunities}

One unanswered question raised by the results that constitutes a limitation of the present series of studies concerns breadth of effects. That is, how might clinical outcomes be further expanded across three dimensions of behavior change: stimulus generalization, response generalization, and maintenance (Stokes \& Baer, 1977)?

Stimulus Generalization. Stimulus generalization refers to the degree to which positive intervention effects obtained in one situation transfer to other situations even in the absence of intervention in those situations. Consider the data for Brian (Study 2) for example. We were successful in eliminating his problem behavior for a specific context, namely, his having to terminate the preferred activity of painting in order to return to other academic activities. It is clear, however, that during the course of a typical school day, Brian might be called upon to terminate a variety of preferred activities (gym, recess, lunch). Therefore, it would be important to extend the context-based approach so that positive outcomes could also be achieved across a variety of preferred situations beyond painting per se. One strategy for producing such stimulus generalization would be to recycle the effective strategy across several preferred situations, a tactic referred to as multiple exemplar training (Stokes \& Baer, 1977). Often, by recycling the effective intervention across as few as three to four situations, positive outcomes will transfer to a large number of other situations not so treated (Carr et al., 1999), a true example of stimulus generalization.

Response Generalization. Response generalization refers to the degree to which positive intervention effects transfer from the initial behavioral target of intervention to other aspects of the individual's behavior repertoire that were not targeted for intervention. Consider the data for Joanne (Study 3), for example. We were successful in eliminating her fear-motivated problem behavior related to certain videos that she wished to avoid watching. Interestingly, however, the teacher reported that the decrease in problem behavior was accompanied by increases in several prosocial behaviors (e.g., more 
on-task behavior, an increase in social overtures to peers, a greater degree of positive affect) that had not been targets of intervention. These observations, though only anecdotal, suggest that the remediation of behavior in certain contexts may be "pivotal," that is, capable of producing widespread behavior change beyond the original target (Koegel, Koegel, Harrower, \& Carter, 1999), a possibility that justifies programmatic research.

Maintenance. Maintenance refers to the degree to which intervention effects last over time. In the present series of studies, we demonstrated that context-based interventions could produce short-term gains in remediating problem behavior and increasing participation in routine contexts. However, we did not assess the durability of intervention. Data suggest that adding skill-building interventions (e.g., teaching the child specific social, communicative, and problem-solving skills) can be useful in extending the effects of context-based intervention over protracted periods of time (Carr et al., 1999). One additional unexplored possibility would be to create systemic changes (e.g., additional staff training, reallocation of personnel, employee incentive systems) to ensure that contextual modifications are not reversed over time, thereby helping to maintain environmental conditions favorable to evoking prosocial behavior while minimizing cues for problem behavior (Knoster, Villa, \& Thousand, 2000). In sum, there are several maintenance-enhancing strategies that are worthy of empirical evaluation with a view to extending the effectiveness of a context-based model of intervention.

\section{Concluding Comment}

Outcome of the present series of studies extends previous research by demonstrating that a context-based approach can be a viable strategy for decreasing problem behavior and increasing prosocial engagement in children with autism spectrum disorders (Carr et al., 2003; Gardner, Cole, Davidson, \& Karan, 1986) in situations characterized by high ecological validity. The approach has the potential to influence behavior broadly, including assisting individuals in gaining functional competencies, improving relationships, participating in inclusive activities, and gaining access to preferred events (Carr et al., 2002). In sum, context-based assessment and intervention offer clinicians the possibility of greatly expanded options for dealing with serious problem behavior, and researchers the possibility of developing a model of problem behavior whose multifactorial nature better captures the complexity of such behavior in naturalistic settings. 


\section{Appendix A \\ Intervention Fidelity Checklists}

Intervention Component

Implemented?

Study I:Transitions between settings or activities

Did the intervention agent present the child with his/her visual schedule prior to the transition?

Did the intervention agent verbally prepare (warn) the child 5 minutes prior to the transition?

Did a peer accompany the child (Darrell only) on the transition?

Did the intervention agent gradually increase the distance from the classroom to the new setting? (Darrell only)

Was the child presented with a "What did I miss?" card 2 minutes before returning to the classroom?

Study 2:Termination of a preferred activity

Did the intervention agent present the child with countdown cards prior to the ending of the preferred activity?

Study 3: Presence of a feared stimulus

Did the intervention agent present the child with a choice between the feared stimulus and another item?

Was the item matched for general content with the feared stimulus?

$\begin{array}{ll}\mathrm{Y} & \mathrm{N} \\ \mathrm{Y} & \mathrm{N} \\ \mathrm{Y} & \mathrm{N} \\ \mathrm{Y} & \mathrm{N} \\ \mathrm{Y} & \mathrm{N} \\ & \\ \mathrm{Y} & \mathrm{N} \\ & \\ \mathrm{Y} & \mathrm{N} \\ \mathrm{Y} & \mathrm{N}\end{array}$

Note: $\mathrm{Y}=$ yes; $\mathrm{N}=$ no.

\section{Appendix B \\ Social Validity (IV)}

Name of child:

Name of intervention agent:

Date:

Intervention session completed

\begin{tabular}{ccccccc}
\hline & Strongly Disagree & & \multicolumn{2}{c}{ Somewhat Agree } & \multicolumn{2}{c}{ Strongly Agree } \\
\hline 2 & 3 & 4 & 5 & 6 & 7 \\
\hline
\end{tabular}

To what extent do you agree or disagree with the following statements? Please circle the number that most clearly reflects your response.

(I) The strategies I learned were easy to use:

$\begin{array}{llllllll}\text { I } & 2 & 3 & 4 & 5 & 6 & 7\end{array}$

(2) The strategies I learned were helpful to me:

\begin{tabular}{lllllll}
\hline & 2 & 3 & 4 & 5 & 6 & 7 \\
\hline
\end{tabular}




\section{Appendix C \\ Social Validity (DV)}

Name of child:

Name of intervention agent:

Date:

Baseline session completed

Intervention session completed

\begin{tabular}{ccccccc}
\hline & Strongly Disagree & & \multicolumn{2}{c}{ Somewhat Agree } & \multicolumn{2}{c}{ Strongly Agree } \\
\hline 1 & 2 & 3 & 4 & 5 & 6 & 7 \\
\hline
\end{tabular}

To what extent do you agree or disagree with the following statements? Please circle the number that most clearly reflects your response.

(I) This child's problem behavior is severe

\begin{tabular}{llllll} 
I & 2 & 3 & 5 & 6 & 7 \\
(2) This child is a danger to him- or herself or others & & & \\
I & 2 & 4 & 5 & 6 & 7 \\
(3) This child is disruptive in this setting & 3 & 5 & 5 & 6 & 7 \\
\hline
\end{tabular}

\section{Authors' Note}

The authors would like to thank Tristram Smith at the University of Rochester Medical Center for critical feedback and Mike Darcy of the Institute for Children with Autism for facilitating this research. This study was based on a doctoral dissertation submitted by the senior author to the Department of Psychology, State University of New York at Stony Brook. Address all correspondence to Sanja I. Cale, School of Education, SUNY Old Westbury, Westbury, N.Y. 11568- 0210; e-mail: cales@oldwestbury.edu.

\section{References}

Albin, R. W., Lucyshyn, J. M., Horner, R. H., \& Flannery, K. B. (1996). Contextual fit for behavior support plans. In L. K. Koegel, R. L. Koegel, \& G. Dunlap (Eds.), Positive behavioral support (pp. 81-98). Baltimore: Paul H. Brookes.

Baker, B. L., Blacher, J., Crnic, K. A., \& Edelbrock, C. (2002). Behavior problems and parenting stress in families of three-year-old children with and without developmental delays. American Journal on Mental Retardation, 107, 433-444.

Bambara, L. M., Koger, F., Katzer, T., \& Davenport, T. A. (1995). Embedding choice in the context of daily routines: An experimental case study. Journal of the Association for Persons with Severe Handicaps, 20, 185-195.

Bijou, S. W., \& Baer, D. M. (1978). Behavior analysis of child development. Englewood Cliffs, NJ: Prentice-Hall. 
Brown, F., Belz, P., Corsi, L., \& Wenig, B. (1993). Choice diversity for people with severe disabilities. Education and Training in Mental Retardation, 12, 318-325.

Bruininks, R. H., Hill, B. K., \& Moreau, L. E. (1988). Prevalence and implications of maladaptive behaviors and dual diagnosis in residential and other service programs. In J. A. Stark, F. J. Menolascino, M. H. Albarelli, \& V. C. Gray (Eds.), Mental retardation and mental health: Classification, diagnosis, treatment, services (pp. 3-24). New York: Springer Verlag.

Carr, E. G. (1977). The motivation of self-injurious behavior: A review of some hypotheses. Psychological Bulletin, 84, 800-816.

Carr, E. G., \& Carlson, J. I. (1993). Reduction of severe behavior problems in the community using a multicomponent treatment approach. Journal of Applied Behavior Analysis, 26, 157-172.

Carr, E. G., Dunlap, G., Horner, R. H., Koegel, R. L., Turnbull, A. P., Sailor, W., et al. (2002). Positive behavior support: Evolution of an applied science. Journal of Positive Behavior Interventions, 4, 4-16.

Carr, E. G., \& Durand, V. M. (1985). Reducing behavior problems through functional communication training. Journal of Applied Behavior Analysis, 18, 111-126.

Carr, E. G., Horner, R. H., Turnbull, A. P., Marquis, J. G., Magito McLaughlin, D., McAtee, M. L., et al. (1999). Positive behavior support for people with developmental disabilities: A research synthesis. Washington, DC: American Association on Mental Retardation.

Carr, E. G., Ladd, M. V., \& Schulte, C. (2008). Validation of the Contextual Assessment Inventory (CAI) for problem behavior. Journal of Positive Behavior Interventions, 10, 91-104.

Carr, E. G., Levin, L., McConnachie, G., Carlson, J., Kemp, D. C., \& Smith, C. E. (1994). Communication-based intervention for problem behavior. Baltimore: Paul H. Brookes.

Carr, E. G., Newsom, C. D., \& Binkoff, J. A. (1980). Escape as a factor in the aggressive behavior of two retarded children. Journal of Applied Behavior Analysis, 13, 101-117.

Carr, E. G., Smith, C. E., Giacin, T. A., Whelan, B. M., \& Pancari, J. (2003). Menstrual discomfort as a biological setting event for severe problem behavior: Assessment and intervention. American Journal of Mental Retardation, 108, 117-133.

Davis, C. A., \& Fox, J. (1999). Evaluating environmental arrangement as setting events: Review and implications for measurement. Journal of Behavioral Education, 9, 77-96.

Dooley, P., Wilczenski, F. L., \& Torem, C. (2001). Using an activity schedule to smooth school transitions. Journal of Positive Behavior Interventions, 3, 57-61.

Dunlap, G., Kern-Dunlap, L., Clarke, S., \& Robbins, F. R. (1991). Functional assessment, curricular revision, and severe behavior problems. Journal of Applied Behavior Analysis, 24, 387-397. 
Flannery, K. B., \& Horner, R. H. (1994). The relationship between predictability and problem behavior for students with severe disabilities. Journal of Behavioral Education, 4, 157-176.

Gardner, W. I., Cole, C. L., Davidson, D. P., \& Karan, O. C. (1986). Reducing aggression in individuals with developmental disabilities: An expanded stimulus control, assessment, and intervention model. Education and Training of the Mentally Retarded, 21, 3-12.

Hersen, M., \& Barlow, D. H. (1976). Single case experimental designs. New York: Pergamon.

Horner, R. H., Dunlap, G., Koegel, R. L., Carr, E. G., Sailor, W., Anderson, J., et al. (1990). Toward a technology of "nonaversive" behavioral support. Journal of the Association for Persons with Severe Handicaps, 15, 125-132.

Iwata, B. A., Dorsey, M. F., Slifer, K. J., Bauman, K. E., \& Richman, G. S. (1982). Toward a functional analysis of self-injury. Analysis and Intervention in Developmental Disabilities, 2, 3-20.

Knoster, T. P., Villa, R. A., \& Thousand, J. S. (2000). A framework for thinking about systems change. In R. A. Villa \& J. S. Thousand (Eds.), Restructuring for caring and effective education (pp. 93-128). Baltimore: Paul H. Brookes.

Koegel, L. K., Koegel, R. L., Harrower, J. K., \& Carter, C. M. (1999). Pivotal response intervention I: Overview of approach. Journal of the Association for Persons with Severe Handicaps, 24, 174-185.

Koegel, R. L., Schreibman, L., Loos, L. M., Dirlich-Wilhelm, H., Dunlap, G., Robbins, F. R., et al. (1992). Consistent stress profiles in mothers of children with autism. Journal of Autism and Developmental Disabilities, 22, 205-216.

Laraway, S., Snycerski, S., Michael, J., \& Poling, A. (2001/2002). The abative effect: A new term to describe the actions of antecedents that reduce operant responding. Analysis of Verbal Behavior, 18, 101-104.

Mace, A. B., Shapiro, E. S., \& Mace, F. C. (1998). Effects of warning stimuli for reinforcer withdrawal and task onset on self-injury. Journal of Applied Behavior Analysis, 31, 679-682.

McAtee, M., \& Carr. E. G., (2004). A Contextual Assessment Inventory for problem behavior: Initial development. Journal of Positive Behavior Interventions, 6, 148-165.

McClannahan, L. E., \& Krantz, P. I. (1999). Activity schedules for children with autism: Teaching independent behavior. Bethesda, MD: Woodbine.

Michael, J. (1982). Distinguishing between discriminative and motivational functions of stimuli. Journal of the Experimental Analysis of Behavior, 37, 144-155.

O’Neill, R. E., Horner, R. H., Albin, R. W., Storey, K., Newton, J. S., \& Sprague, J. R. (1997). Functional assessment and program development for problem behavior. Pacific Grove, CA: Brooks/Cole.

Quill, K. (1995). Visually cued instruction for children with autism and pervasive developmental disorders. Focus on Autistic Behavior, 10, 10-20. 
Schmit, J., Alper, S., Raschke, D., \& Ryndak, D. (2000). Effects of using a photographic cueing package during routine school transitions with a child who has autism. Mental Retardation, 38, 131-137.

Scotti, J. R., Evans, I. M., Meyer, L. H., \& Walker, P. (1991). A meta-analysis of intervention research with problem behavior: Treatment validity and standards of practice. American Journal on Mental Retardation, 96, 233-256.

Stokes, T. F., \& Baer, D. M. (1977). An implicit technology of generalization. Journal of Applied Behavior Analysis, 10, 349-367.

Touchette, P. E., MacDonald, R. F., \& Langer, S. N. (1985). A scatter plot for identifying stimulus control of problem behavior. Journal of Applied Behavior Analysis, 18, 343-351.

Tustin, R. (1995). The effects of advance notice of activity transitions on stereotypic behavior. Journal of Applied Behavior Analysis, 28, 91-92.

\section{Bios}

Sanja I. Cale, PhD, BCBA, is an assistant professor in the School of Education at the State University of New York at Old Westbury. Her teaching and research interests include challenging behaviors, PBS-based interventions for children with disabilities, and evaluations of support services for families and professional staff in public school settings.

Edward G. Carr, PhD, was a leading professor in the Department of Psychology at the State University of New York at Stony Brook. His research interests included autism, community integration, family support, systems change, biomedical factors, and problem behavior.

Audrey Blakeley-Smith, PhD, is an assistant professor in the Department of Psychiatry at the University of Colorado at Denver Health Sciences Center. Her current research interests include school-based interventions and anxiety treatment for children with Autism Spectrum Disorders (ASD).

Jamie S. Owen-DeSchryver, $\mathrm{PhD}$, is an assistant professor of psychology at Grand Valley State University in Allendale, Michigan. Her current research interests include evaluation of school-based strategies for preschoolers with ASD and professional development for public school personnel serving students with ASD. 